\title{
The Association between Circadian Rhythms and Paediatric Obesity
}

\author{
Jessica Rosen ${ }^{1}$ and Colin M. Shapiro² \\ ${ }^{1}$ No affiliations \\ ${ }^{2}$ Departments of Psychiatry and Ophthalmology, University of Toronto; Youthdale Child and Adolescent Sleep Centre; \\ West Parry Sound Health Centre; ON, Canada
}

\begin{abstract}
In this synthesis, we attempt to present some perspective on the impact of circadian rhythms on childhood and adolescent obesity, a correlation that is often proposed, but frequently overlooked in comparison to adult and generalized sleep research. Here, we will review the extant literature, discuss the proposed theories and mechanisms, and provide a more comprehensive review as to the efficacy of targeting and further exploring the relationship of circadian rhythms and obesity determinants in paediatric populations.
\end{abstract}

Key Words: Pediatric obesity; Circadian rhythms; Sleep; Obesity; Review

Received: January 30, 2020 Accepted: February 2, 2020

Corresponding author: Colin M. Shapiro, BSC (Hon), MBBCh, PhD, MRCPsych, FRCP (C), Departments of Psychiatry and Ophthalmology, University of Toronto, 227 Victoria St, Toronto, ON M5B 1T8, Canada.

Tel: 1-416-703-0505, Fax: 1-416-703-0507, E-mail: colinshapiro@rogers.com

(a) This is an Open Access article distributed under the terms of the Creative Commons Attribution Non-Commercial License (https://creativecommons.org/licenses/by$\mathrm{nc} / 4.0)$ which permits unrestricted non-commercial use, distribution, and reproduction in any medium, provided the original work is properly cited.

\section{INTRODUCTION}

Childhood overweight and obesity are major public health concerns, posing significant health-related burdens for both individuals and society. The World Health Organization (WHO) defines overweight in children ages 5-19 as having a body-mass index (BMI)-for-age greater than one standard deviation above the Growth Reference Median, and greater than two standard deviations when defining obesity [1]. Although the prevalence of childhood obesity has shown a degree of deceleration in some contexts, worldwide estimates still indicate that over 340 million children and adolescents ages 5-19 are overweight. This number is even more alarming when put in a chronological perspective: the prevalence of overweight and obesity among this age group has risen from just $4 \%$ in 1975 , to over $18 \%$ in 2016 . If current trends continue in the same trajectory, this number will reach 70 million by 2025 [2].

As a consequence of the increasing prevalence and severity of obesity, there has been an increase in the emergence of obesity-associated psychosocial and clinical morbidities. These include but are not limited to "Non-alcoholic fatty liver disease, sleep apnea, type 2 diabetes, asthma, cardiovascular disease, hypercholesterolemia, glucose intolerance and insulin resistance, skin conditions, menstrual abnormalities, impaired balance, orthopedic problems, and poor learning skills, which can lead to social discrimination" [3]. More importantly, childhood obesity does not only affect children when they are young, but also seems to impose adverse consequences on premature mortality and physical morbidities later in adulthood [4].

The increasing consciousness of weight-imposed implications, in amalgamation with the rising numerical trends, has led to the pertinent need to address promoting and aggravating factors of obesity and its associated comorbidities. Several preventative and treatment strategies have been proposed examining the role of dietary patterns, physical activity levels, and environmental and sociocultural factors affecting weight management. Sleep measures have also been recently recognized as potential risk factors for weight gain, leading to a recent surge in scientific attention. Specifically, the sleep-wake cycle is one of many important cyclical daily functions encompassed by circadian rhythms, which is the daily metabolic cycle of mammals primarily synchronized or entrained from exposure to the Earth's 24-hour light-dark cycle [5]. In this synthesis, we attempt to present some perspective on the impact of circadian rhythms on childhood and adolescent obesity, a correlation that is often proposed, but frequently overlooked in comparison to adult and generalized sleep research. Here, we will review the extant literature, discuss the proposed theories and mechanisms, 
and provide a more comprehensive review as to the efficacy of targeting and further exploring the relationship of circadian rhythms and obesity determinants in paediatric populations.

\section{SLEEP PATTERNS AND OBESITY RISK}

\section{Sleep Duration and Weight Gain}

The rate of childhood obesity in the population has increased in parallel with the rate of reported sleep deprivation. Worldwide data reports show a secular decline of 0.75 minutes per year in children's sleep duration since 1905 to 2008, coupled with a slight decrease in child sleep recommendations [6]. However, statistics for childhood average sleep duration have been, and still remain, well below provided recommendations. The National Sleep Foundation recommends the following sleep hours: 14-17 for newborns (0-3 months), $12-15$ for infants (4-11 months), 11-14 for toddlers (12-24 months), 10-13 for preschoolers (3-5 years), 9-11 for school age children (6-13 years), and 8-10 for teenagers ( $14-17$ years) [7]. In 2014, the National Sleep Foundation conducted a national report in the United States showing that school children slept a combined weekly average of approximately 8.5 hours per night and teenagers had their average at approximately 7.6 hours per night, both being below their recommended ranges [8].

There is a growing body of epidemiological cross-sectional and longitudinal evidence associating this trend of insufficient sleep patterns with weight gain [4,9-11]. This relationship is particularly significant within children and adolescents, suggesting that these age groups have an increased vulnerability towards the reported harmful health effects of inadequate sleep. A systematic review and meta-analysis were conducted in 2008, examining short sleep duration and obesity prevalence in a cohort of 30,000 child participants from around the world. Results from this review deduced that the pooled odds ratio for children was 1.89 (95\% confidence interval: 1.46-2.43) for the relationship of short duration of sleep and obesity [12]. A more recent meta-analysis including worldwide data from over 50,000 children and adolescents, confirmed this finding: participants with shorter sleep duration (10 hours or under) were $76 \%$ more likely (95\% confidence interval: $1.39-$ 2.23) to be overweight or obese and to present with greater annual increases in BMI, when compared to participants with longer sleep durations. Furthermore, with every additional increment of one sleep hour of sleep per day, annual BMI gain declined by $0.05 \mathrm{~kg} / \mathrm{m}^{2}$, representative of a $21 \%$ reduction [13].

Longitudinal studies following children over the course of a few years have shown similar correlations between the two variables. A 2016 study conducted in Brazil examined the relationship between short sleep duration and weight gain in the first years of life. Children were recruited at birth (4,231 participants), and were subsequently followed up with home visits at one, two, and four years of age. Accounting for sociodemographic and diverse sleep characteristics, the study concluded that children who slept fewer than 10 hours per night at the time of all follow-up appointments were more likely to be overweight or obese by the age of four $(13.3 \%$ or
201 children) [14]. In the United States, longitudinal data on infant weight gain status has likewise shown similar prevalence rates, with $12.1 \%$ of infants in the same age group being classified as overweight or obese in 2009-2010 [15]. In Australia, 939 students (ages 7-12) were followed for four years to examine the longitudinal relationship between BMI and sleep durations. Results indicate that children in the upper tercile of sleep (above the mean sleep time for their age) had a lower weight gain of $2.3 \mathrm{~kg}$ and a lower BMI increase of $0.45 \mathrm{~kg} / \mathrm{m}^{2}$ in comparison to children in the lowest sleep tercile (below the mean sleep time for their age), independent of physical activity and baseline BMI measures [16]. In Canada, a similar longitudinal study was conducted: 1,900 preadolescent children aged 10 years old were followed up for three years. The results indicated that short-sleep trajectory (less than 10.5 hours per day) was associated with a higher odds ratio of being overweight than those sleeping 11 hours per day and above. These results were adjusted for confounding factors indicative of the preadolescence phase, such as lifestyle modifications, pubertal changes, and sleep habits [17]. Although this particular study adjusted for confounding variables, there is a lack of widespread consistency in confounding variable adjustment across the literature being produced, making it difficult to deduce causal inferences. As well, there is a scarcity in longitudinal data spanning more than a few years, or going past young childhood age parameters. Despite these limitations in research design and data specification, the majority of current evidence strongly favors a linear correlation between shortened sleep duration and increased weight gain in paediatric populations. Future research should increase specificity, and focus on assessing the long-term effects of desynchronized sleep and wake cycles on circadian rhythms and BMI scores in young children and adolescents.

\section{Sleep Timing, Feeding Times, Caloric Intake, and Weight Gain}

A number of recent observational studies have taken the proposed relationship between sleep duration and obesity one step further, addressing the association of sleep to obesogenic behaviors. Although the relationship between restricted sleep timing and total energy expenditure shows mixed and subjective, individualized results [18], there exists a growing amount of evidence indicating that sleep timing has a prominent influence in weight management [19]. In accordance with sleep-wake cycle regulation, children who show increased evening caloric intake subsequently have little to no morning caloric intake. This dysregulation of meal timing in dark-light exposure has been shown to be positively correlated to an increase in weight gain, adiposity, and overall BMI scores in paediatric populations [20-24]. Many studies posit that perhaps these later feeding times could be a psychological result of chronotypes (nocturnal versus early bird tendencies): adolescents with evening chronotypes reportedly have phase delays in diurnal eating patterns, resulting in a higher prevalence of breakfast skipping and a shift in energy intake towards later in the day [24,25]. However, some studies show in contrast that this trend is potentially not a primary result of chronotypes, but instead caused by a mis- 
alignment in internal circadian clocks where overweight or obese individuals have food intake timing dissociated from their preferred chronotype [26]. This concept is also relevant in the context of "social jetlag," emphasizing prominent discrepancies between circadian clocks and social rhythms in adolescents [27]. After adjustment, social jetlag in adolescents shows a positive correlation to adiposity variables, including a greater body fat percentage, fat mass, fat mass index, waist-to-hip ratio, and BMI score [28-30]. Longitudinal studies, however, are still needed to prove causality outside of and within the adolescent phase.

A relationship has also been deduced between the timing of the first meal and bedtimes in school aged children, suggesting that those who consume daily breakfasts have earlier sleep trajectories $[31,32]$. The majority of the evidence in these studies, however, point to the conclusion that bedtime in conjunction with wakefulness hours, as opposed to sleep duration measures, have a more pronounced relationship with obesity measures. In a recent 2019 randomized controlled trial, children $8^{-}-11$ years old were recruited to examine the relationship between nocturnal sleep time and obesogenic behaviors such as dietary intake and intake timing [18]. Although both later bedtimes and total sleep duration were shown to be associated with later last meals, each variable had an independent effect on obesity risk factors. In specific, later bedtimes were correlated to greater daily caloric intakes and percent calorie (kcal) from fat, as well greater intakes of calories post dinner meals. In comparison, decreased sleep duration was solely linked to increased standardized BMI scores (zBMI). This conclusion is suggestive that in school-aged children, later bedtimes can be a more predictive measures of dietary obesity risk factors [18]. It is important to note that studies examining infant feeding patterns and circadian dysregulation have confirmed these obesogenic correlations starting from as early as infancy $[33,34]$. In a recent study, mothers from a birth cohort of 349 children were recruited and asked to report their child's feeding patterns at 12 months accompanied with the subsequent growth and weight status one year following. The results showed that infants predominantly fed at nights had a higher BMI score from 12 to 24 months of age and an increased risk of becoming overweight by 24 months, suggesting the prominent role of daily energy consumption distribution in weight regulation from early infancy [33].

\section{Underlying Biological Mechanisms}

It is important to review and take note of the underlying biological mechanisms that could be accounting for increased dietary obesogenic behaviors in relationship to altered circadian sleep schedules in children. Many mechanisms have been proposed, ranging from appetite hormone regulation, homeostatic eating behavior regulation, and glycemic alterations. One of the proposed mechanisms centered on appetite regulation hormones (leptin, ghrelin) and their dependency on sleep timing, quality, and duration [35]. Studies in this area suggest that insufficient sleep patterns can result in alterations of hormonal pathways [36]. Experimental studies with adolescents and school-aged children show that sleep re- striction is associated with decreases in leptin levels, and increases in ghrelin levels and reported hunger cues, after controlling for energy expenditure and overall caloric intake [37,38]. These results highlight a potential pathway existing between food reinforcement and an individual's motivation to obtain food, when sleep duration is reduced or when overall circadian sleep patterns become dysregulated [39-42].

Another proposed mechanism centers on the influence of the autonomic nervous system, specifically looking at sleep-dominant parasympathetic activity levels. Frequent nocturnal awakenings have been shown to increase states of wakefulness, leading to decreased parasympathetic activity and increased sympathetic activity (norepinephrine release, elevated blood pressure and heart rates, increased muscle nerve activity). This subsequently results in increased activity of the hypothalamic pituitary adrenal system, which causes the secretion of steroid and glucose-linked hormones such as cortisol [43]. Some experiments [44], but not all proposed experiments [45], have found sleep restriction to have a direct impact on circadian-routed cortisol secretion. The 24-hour profile of cortisol is characterized by peak early morning levels, declining levels during the day, and a period of minimal activity in the evening and first part of the night (quiescent period), followed by a sharp circadian increase later in the night [35]. When examining the role of sleep in cortisol predictors, studies have shown a dose-response relationship in which evening cortisol levels show greater discrepancies when sleep duration is altered. Specifically, evening cortisol levels appear higher when subjects are in a state of sleep debt [46]. In young children, this trend points to an increase in awakening, morning, and afternoon cortisol levels when participants present with fragmented sleep patterns or poorer sleep quality [47-51]. Nevertheless, studies examining the association between appetite controlling hormones and sleep timing, quality, and duration remain largely mixed, with few but limited replicable findings [44,45,52-54].

Studies have also been published evaluating the epidemiological data between sleep, obesity, and insulin resistance. Results have shown an inverse association between sleep duration and homeostasis model assessments of insulin resistance (insulin resistance measures calculated from fasting glucose levels) $[55,56]$. However, the data obtained for paediatric studies is limited, showing that reduced sleep duration may predispose children to increased insulin sensitivity and blood glucose levels, but that children may also have adaptive mechanisms that make them more resilient to the effects of sleep restriction when encountered short-term [57]. Overall, data is still inconsistent and varied, showing low ecological validity between sleep and glucose homeostasis within community-based studies [58]. There has also been a limited amount of experimental studies looking more in depth at the effects of sleep on insulin signaling at a tissue-level. A clinical trial in Chicago showed that when sleep duration was restricted in lean, healthy adults for a period of four nights, there was a 30\% reduction of cellular insulin sensitivity in adipocytes. These results deduce a potential link between sleep duration and cellular insulin sensitivity in adipocytes through an impairment in the phosphorylation of Akt, 
a crucial step of the phosphatidylinositol 3-kinase (P13K) pathway that mediates the metabolic actions of insulin [59]. Other studies have focused more on tissue-specific epigenetic changes in relation to circadian clock gene expression, uncovering interrelationships between sleep homeostasis, circadian rhythmicity, and metabolism [60,61]. Specifically, a clinical study in England found that one week of insufficient sleep reduced the amplitude of circadian rhythms in gene expression, affecting genes involved in chromatin remodeling, stress responses, and inflammatory pathways [61]. These studies are novel, and as such, still require replicability, extended sample sizes, and paediatric-specific cohort analysis.

\section{EFFECTIVENESS OF SLEEP/CIRCADIAN IMPROVEMENT INTERVENTIONS}

Although there have been consistent linear relationships observed between circadian sleep-wake disruptions and obesity measures, the question still remains as to whether sleep improvement programs can serve as effective tools for improving metabolic health in paediatric patient populations. There have been numerous research attempts assessing the efficacy of sleep education programs for children and adolescents [62-68], however, metabolic alterations and weight management have not generally been primary outcomes of interest. A recent paediatric study, however, examined the results of extending sleep duration to assess variables in food intake and leptin and ghrelin levels [38]. Following sleep extension for a period of three weeks, daily caloric intake declined by $134 \mathrm{kcal}$ per day, body weight mass declined by $0.22 \mathrm{~kg}$, and leptin levels decreased by $18.6 \%$ in comparison to the control group.

Several studies, primarily looking at preschool-aged children, show there to be positive effects of promoting healthier sleep patterns in children who present with behavioral sleep disorders [6971]. Further studies have built on this framework to be able to assess the validity of the study findings in children who have reduced sleep duration tendencies. There exists a recent and ongoing study that is assessing the implications of brief sleep interventions and the effects of these on eating behaviors in children [72]. Prior to implementation, this study had a pilot program that involved children ages 8 to 11 years old who slept an average of 9.5 hours per night or less during the school week. Children were randomized into a control group (unchanged sleep patterns), or an intervention group in which families were provided with effective behavioral strategies and follow-up problem solving strategies to increase sleep duration. Preliminary results from this pilot study showed positive, acute enhancement in school-aged children's average sleep time, as well as plausible signals that sleep changes could create altered food motivation [72].

Overall, the efficacy and validity of the current research available on sleep interventions for children and adolescents should be interpreted with some caution. The majority of these studies have been carried out with small recruitment cohorts, leading to an increased chance of confounding variables and low study validity. As well, in these studies, most of the data obtained from these studies is extracted from self- or parent-reported questionnaires, control groups are often left out, increased sleep hours on weekends are not properly accounted for, and weight management indicators are secondary data extractions. All of these limitations serve to highlight the presence of potential bias in study results, as well as the need for more interventions addressing the relationship between sleep patterns and weight management in a multifaceted approach targeting dietary intake, feeding times and patterns, and subsequent sleep duration and timing.

\section{BIDIRECTIONALITY AND CAUSALITY}

The strongest limitation in the presented research is the degree of ambiguity associated with the causality of sleep and obesity. That is to say, does the formation of unhealthy sleep patterns cause weight gain, or does weight gain lead to the formation of unhealthy sleep patterns? Perhaps there exists mediating variables which are caused by restricted sleep durations, that have the potential of increasing individualized susceptibility to obesogenic tenancies. For instance, a plausible underlying mechanism of obese tendencies in sleep restricted populations is food intake regulation altered by the neurotransmitter hypocretin (orexin) [73-75]. Hypocretin is linked to stress-induced states of hyperarousal characterized by increased insomnia, anxiety, and daytime fatigue [73]. Hypocretin is also embedded in autonomic functions of sympathetic activation, and has been shown to have the potential to activate appetite regulating neurons and inhibit appetite suppressing neurons, which together can show an underlying mediating variable as to the association of weight gain and sleep disturbance [73-75]. There also exists a plethora of robust and controversial information linking food ingestion to sleep, such as the ingestion of cow's milk, herbal products, sleep-promoting fruits (cherries or kiwifruits), as well as the overall carbohydrate and fat percent breakdown of meals [76-84]. In specific, cow's milk contains levels of the amino acid Ltryptophan, a precursor to serotonin and melatonin, two hormones that play an important role in sleep promotion [85]. A recent study conducted in Canada with 156 children (ages 3-18) diagnosed with primary parasomnia, found that $84 \%$ of participants treated with L-tryptophan experienced significant improvements in their parasomnia symptoms [86]. It is important to note that although there is documented evidence of the physiological connection between food and sleep, the clinical relevance of these findings is still underwhelming and requires further causal investigations.

\section{CONCLUSION}

This synthesis illustrates the complex interaction between obesity and circadian-routed sleep patterns. Although there exists concrete evidence showing a direct association between the two variables, further investigation is needed to correct widespread limitations and point to a stronger deduction of causality. Current research examining circadian rhythms and paediatric obesity is limited by the availability of longitudinal data. Furthermore, research 
is tainted with the presence of bias and reduced validity as a result of the predominant use of questionnaires, reduced sample sizes, lack of control groups, and a lack of cultural and socioeconomic diversity in recruitment cohorts [5,30,38,43,87-90]. Future studies should aim to address these concerns through the inclusion of long-term exposure research, more accurate and specific objective measurements of sleep, control for confounding variables, and more widespread cohorts spanning diverse environments and socioeconomic and cultural backgrounds. Studies should also explore the connection between light-dark cycles and its effect on feeding times, driving factors for food intake, adiposity measures, and hormone regulation, to gain a more comprehensive understanding of circadian metabolic dependency.

From a public health perspective, although primitive, it is evident that modern youth intake and sleep patterns and sleep timing are substantially contributing to the current global obesity epidemic. It is thus critical to further investigate this link to properly create and ameliorate current policies and behavioral interventions targeting children and adolescents who are at an increased risk of becoming overweight or obese. In particular, more work needs to be done in the design and execution of interventions and policy analysis. Given the dynamic nature between obesity and sleep patterns during childhood and adolescence, more holistic approaches need to be integrated in the development of prevention and treatment strategies to encompass lifestyles habit formation. As it has been clearly depicted, sleep and obesity does not entail a one-way relationship, and this is certainly not unidirectional in its associated physiological and behavioral impacts. As such, measures need to be taken to account for all factors, both primary and secondary, that affect this relationship: studies should aim to address both sleep measures and obesogenic correlates through providing resources and integrated educational awareness on the relationships between chronotypes, sleep timing, food intake, and caloric distribution patterns. It is of key importance, however, that future studies and interventions explore and advise on all aspects of the sleep-continuum and its relationship with obesity. In research data, there is the suggestion of a U-shaped relationship with sleep duration and observed adiposity/BMI measures [91-93]. Restricted sleep duration can lead to an increased risk of poor health outcomes associated with weight gain. However, too much sleep can also lead to similar outcomes associated with restricted sleep schedules. Future studies should further examine this U-shaped relationship, and through this, provide novel data of its implications on obesogenic behaviors to better compose sleep education curriculums for children, adolescents, and their caregivers.

\section{Acknowledgments}

None

\section{Conflicts of Interest}

The authors have no potential conflicts of interest to disclose.
Author Contributions

Conceptualization: Colin M. Shapiro. Data curation: Jessica Rosen. Project administration: Colin M. Shapiro. Resources: Colin M. Shapiro. Supervision: Colin M. Shapiro. Writing-original draft: Jessica Rosen. Writing_review \& editing: Jessica Rosen, Colin M. Shapiro.

\section{ORCID iDs}

\section{Jessica Rosen (iD}

https://orcid.org/0000-0002-4538-7267

Colin M. Shapiro (D)

https://orcid.org/0000-0002-2231-0427

\section{REFERENCES}

1. World Health Organization. Obesity and overweight. Available at: https:// www.who.int/news-room/fact-sheets/detail/obesity-and-overweight. Accessed July 15, 2019.

2. World Health Organization, Commission on Ending Childhood Obesity. Facts and figures on childhood obesity. Available at: https://www.who.int/ end-childhood-obesity/facts/en/. Accessed July 15, 2019.

3. Aceves-Martins M, Llauradó E, Tarro L, Solà R, Giralt M. Obesity-promoting factors in Mexican children and adolescents: challenges and opportunities. Glob Health Action 2016;9:29625.

4. Reilly JJ, Kelly J. Long-term impact of overweight and obesity in childhood and adolescence on morbidity and premature mortality in adulthood: systematic review. Int J Obes (Lond) 2011;35:891-898.

5. Pereira LR, Moreira FP, Reyes AN, Bach SL, Amaral PLD, Motta JDS, et al. Biological rhythm disruption associated with obesity in school children. Child Obes 2019;15:200-205.

6. Matricciani L, Olds T, Petkov J. In search of lost sleep: secular trends in the sleep time of school-aged children and adolescents. Sleep Med Rev 2012; 16:203-211.

7. National Sleep Foundation. National Sleep Foundation recommends new sleep times. Available at: https://www.sleepfoundation.org/press-release/ national-sleep-foundation-recommends-new-sleep-times. Accessed July $17,2019$.

8. National Sleep Foundation. 2014 Sleep in America ${ }^{\circledR}$ Poll Sleep In The Modern Family: summary of findings. Available at: https://www.sleepfoundation. org/sites/default/files/inline-files/2014-NSF-Sleep-in-America-poll-summary-of-findings---FINAL-Updated-3-26-14-.pdf. Accessed July 17, 2019.

9. Gonnissen HK, Adam TC, Hursel R, Rutters F, Verhoef SP, Westerterp-Plantenga MS. Sleep duration, sleep quality and body weight: parallel developments. Physiol Behav 2013;121:112-116.

10. Chaput J, Tremblay A. Insufficient sleep as a contributor to weight gain: an update. Curr Obes Rep 2012;1:245-256.

11. Magee L, Hale L. Longitudinal associations between sleep duration and subsequent weight gain: a systematic review. Sleep Med Rev 2012;16:231-241.

12. Cappuccio FP, Taggart FM, Kandala NB, Currie A, Peile E, Stranges S, et al. Meta-analysis of short sleep duration and obesity in children and adults. Sleep 2008;31:619-626.

13. Ruan H, Xun P, Cai W, He K, Tang Q. Habitual sleep duration and risk of childhood obesity: systematic review and dose-response meta-analysis of pospective cohort studies. Sci Rep 2015;5:16160.

14. Halal CS, Matijasevich A, Howe LD, Santos IS, Barros FC, Nunes ML. Short sleep duration in the first years of life and obesity/overweight at age 4 years: a birth cohort study. J Pediatr 2016;168:99-103.

15. Ogden CL, Carroll MD, Kit BK, Flegal KM. Prevalence of obesity and trends in body mass index among US children and adolescents, 1999-2010. JAMA 2012;307:483-490.

16. O'Dea JA, Dibley MJ, Rankin NM. Low sleep and low socioeconomic status predict high body mass index: a 4-year longitudinal study of Australian schoolchildren. Pediatr Obes 2012;7:295-303.

17. Seegers V, Petit D, Falissard B, Vitaro F, Tremblay RE, Montplaisir J, et al. Short sleep duration and body mass index: a prospective longitudinal study 
in preadolescence. Am J Epidemiol 2011;173:621-629.

18. Klingenberg L, Sjödin A, Holmbäck U, Astrup A, Chaput JP. Short sleep duration and its association with energy metabolism. Obes Rev 2012;13: 565-577.

19. Allison KC, Goel N, Ahima RS. Delayed timing of eating: impact on weight and metabolism. Curr Obes Rep 2014;3:91-100.

20. Maffeis C, Provera S, Filippi L, Sidoti G, Schena S, Pinelli L, et al. Distribution of food intake as a risk factor for childhood obesity. Int J Obes Relat Metab Disord 2000;24:75-80.

21. Roßbach S, Diederichs T, Nöthlings U, Buyken AE, Alexy U. Relevance of chronotype for eating patterns in adolescents. Chronobiol Int 2018;35:336347.

22. Timlin MT, Pereira MA, Story M, Neumark-Sztainer D. Breakfast eating and weight change in a 5-year prospective analysis of adolescents: project EAT (Eating Among Teens). Pediatrics 2008;121:e638-e645.

23. Eng S, Wagstaff DA, Kranz S. Eating late in the evening is associated with childhood obesity in some age groups but not in all children: the relationship between time of consumption and body weight status in U.S. children. Int J Behav Nutr Phys Act 2009;6:27.

24. Karatzi K, Moschonis G, Choupi E, Manios Y; Healthy Growth Study group. Late-night overeating is associated with smaller breakfast, breakfast skipping, and obesity in children: The Healthy Growth Study. Nutrition 2017; 33:141-144.

25. Vilela S, Oliveira A, Severo M, Lopes C. Chrono-nutrition: the relationship between time-of-day energy and macronutrient intake and children's body weight status. J Biol Rhythms 2019;34:332-342.

26. Muñoz JSG, Cañavate R, Hernández CM, Cara-Salmerón V, Morante JJH. The association among chronotype, timing of food intake and food preferences depends on body mass status. Eur J Clin Nutr 2017;71:736-742.

27. Roenneberg T, Wirz-Justice A, Merrow M. Life between clocks: daily temporal patterns of human chronotypes. J Biol Rhythms 2003;18:80-90.

28. Malone SK, Zemel B, Compher C, Souders M, Chittams J, Thompson AL, et al. Social jet lag, chronotype and body mass index in 14-17-year-old adolescents. Chronobiol Int 2016;33:1255-1266.

29. Parsons MJ, Moffitt TE, Gregory AM, Goldman-Mellor S, Nolan PM, Poulton R, et al. Social jetlag, obesity and metabolic disorder: investigation in a cohort study. Int J Obes (Lond) 2015;39:842-848.

30. Stoner L, Castro N, Signal L, Skidmore P, Faulkner J, Lark S, et al. Sleep and adiposity in preadolescent children: the importance of social jetlag. Child Obes 2018;14:158-164

31. Thivel D, Isacco L, Aucouturier J, Pereira B, Lazaar N, Ratel S, et al. Bedtime and sleep timing but not sleep duration are associated with eating habits in primary school children. J Dev Behav Pediatr 2015;36:158-165.

32. Spaeth AM, Hawley NL, Raynor HA, Jelalian E, Greer A, Crouter SE, et al. Sleep, energy balance, and meal timing in school-aged children. Sleep Med 2019;60:139-144

33. Cheng TS, Loy SL, Toh JY, Cheung YB, Chan JK, Godfrey KM, et al. Predominantly nighttime feeding and weight outcomes in infants. Am J Clin Nutr 2016;104:380-388.

34. Xu SY, Li X, Zheng CX, Wang WM, Yang TT, Wu YY, et al. [Effects of end time of night feeding on the growth and development of infants/toddlers]. Zhongguo Dang Dai Er Ke Za Zhi 2018;20:840-843.

35. Leproult R, Van Cauter E. Role of sleep and sleep loss in hormonal release and metabolism. Endocr Dev 2010;17:11-21.

36. Spiegel K, Tasali E, Penev P, Van Cauter E. Brief communication: sleep curtailment in healthy young men is associated with decreased leptin levels, elevated ghrelin levels, and increased hunger and appetite. Ann Intern Med 2004;141:846-850.

37. Bosy-Westphal A, Hinrichs S, Jauch-Chara K, Hitze B, Later W, Wilms B, et al. Influence of partial sleep deprivation on energy balance and insulin sensitivity in healthy women. Obes Facts 2008;1:266-273.

38. Hart CN, Carskadon MA, Considine RV, Fava JL, Lawton J, Raynor HA, et al. Changes in children's sleep duration on food intake, weight, and leptin. Pediatrics 2013;132:e1473-e1480.

39. Epstein LH, Leddy JJ. Food reinforcement. Appetite 2006;46:22-25.

40. St-Onge MP, Roberts AL, Chen J, Kelleman M, O'Keeffe M, RoyChoudhury A, et al. Short sleep duration increases energy intakes but does not change energy expenditure in normal-weight individuals. Am J Clin Nutr 2011;94:410-416.
41. Brondel L, Romer MA, Nougues PM, Touyarou P, Davenne D. Acute partial sleep deprivation increases food intake in healthy men. Am J Clin Nutr 2010;91:1550-1559.

42. Markwald RR, Melanson EL, Smith MR, Higgins J, Perreault L, Eckel RH, et al. Impact of insufficient sleep on total daily energy expenditure, food intake, and weight gain. Proc Natl Acad Sci U S A 2013;110:5695-5700.

43. Jarrin DC, McGrath JJ, Drake CL. Beyond sleep duration: distinct sleep dimensions are associated with obesity in children and adolescents. Int J Obes (Lond) 2013;37:552-558.

44. Nedeltcheva AV, Kilkus JM, Imperial J, Kasza K, Schoeller DA, Penev PD. Sleep curtailment is accompanied by increased intake of calories from snacks. Am J Clin Nutr 2009;89:126-133.

45. Omisade A, Buxton OM, Rusak B. Impact of acute sleep restriction on cortisol and leptin levels in young women. Physiol Behav 2010;99:651-656.

46. Kumari M, Badrick E, Ferrie J, Perski A, Marmot M, Chandola T. Self-reported sleep duration and sleep disturbance are independently associated with cortisol secretion in the Whitehall II study. J Clin Endocrinol Metab 2009;94:4801-4809.

47. Kristenson M, Lindfors P, Lundberg U, Harris A, Hansen Å, Garvin P, et al. The role of saliva cortisol measurements in health and disease: a matter of theory and methodology. Int J Behav Med 2010:17(Suppl 1):S206-S206.

48. Brand S, Furlano R, Sidler M, Schulz J, Holsboer-Trachsler E. 'Oh, baby, please don't cry!': in infants suffering from infantile colic hypothalamic-pituitary-adrenocortical axis activity is related to poor sleep and increased crying intensity. Neuropsychobiology 2011;64:15-23.

49. Scher A, Hall WA, Zaidman-Zait A, Weinberg J. Sleep quality, cortisol levels, and behavioral regulation in toddlers. Dev Psychobiol 2010;52:44-53.

50. El-Sheikh M, Buckhalt JA, Keller PS, Granger DA. Children's objective and subjective sleep disruptions: links with afternoon cortisol levels. Health Psychol 2008;27:26-33.

51. Mueller AA, Kalak N, Schwenzer-Zimmerer K, Holsboer-Trachsler E, Brand S. Cortisol levels and sleep patterns in infants with orofacial clefts undergoing surgery. Neuropsychiatr Dis Treat 2014;10:1965-1972.

52. Pejovic S, Vgontzas AN, Basta M, Tsaoussoglou M, Zoumakis E, Vgontzas A, et al. Leptin and hunger levels in young healthy adults after one night of sleep loss. J Sleep Res 2010;19:552-558.

53. Schmid SM, Hallschmid M, Jauch-Chara K, Wilms B, Benedict C, Lehnert $\mathrm{H}$, et al. Short-term sleep loss decreases physical activity under free-living conditions but does not increase food intake under time-deprived laboratory conditions in healthy men. Am J Clin Nutr 2009;90:1476-1482.

54. Simpson NS, Banks S, Dinges DF. Sleep restriction is associated with increased morning plasma leptin concentrations, especially in women. Biol Res Nurs 2010;12:47-53.

55. Hitze B, Bosy-Westphal A, Bielfeldt F, Settler U, Plachta-Danielzik S, Pfeuffer $M$, et al. Determinants and impact of sleep duration in children and adolescents: data of the Kiel Obesity Prevention Study. Eur J Clin Nutr 2009;63:739-746

56. Matthews KA, Dahl RE, Owens JF, Lee L, Hall M. Sleep duration and insulin resistance in healthy black and white adolescents. Sleep 2012;35:13531358.

57. Klingenberg L, Chaput JP, Holmbäck U, Visby T, Jennum P, Nikolic M, et al. Acute sleep restriction reduces insulin sensitivity in adolescent boys. Sleep 2013;36:1085-1090.

58. Sadeh A, Lavie P, Scher A, Tirosh E, Epstein R. Actigraphic home-monitoring sleep-disturbed and control infants and young children: a new method for pediatric assessment of sleep-wake patterns. Pediatrics 1991;87:494-499.

59. Broussard JL, Ehrmann DA, Van Cauter E, Tasali E, Brady MJ. Impaired insulin signaling in human adipocytes after experimental sleep restriction: a randomized, crossover study. Ann Intern Med 2012;157:549-557.

60. Cedernaes J, Osler ME, Voisin S, Broman JE, Vogel H, Dickson SL, et al. Acute sleep loss induces tissue-specific epigenetic and transcriptional alterations to circadian clock genes in men. J Clin Endocrinol Metab 2015;100: E1255-E1261

61. Möller-Levet CS, Archer SN, Bucca G, Laing EE, Slak A, Kabiljo R, et al. Effects of insufficient sleep on circadian rhythmicity and expression amplitude of the human blood transcriptome. Proc Natl Acad Sci U S A 2013;110: E1132-E1141.

62. Tan E, Healey D, Gray AR, Galland BC. Sleep hygiene intervention for youth aged 10 to 18 years with problematic sleep: a before-after pilot study. 
BMC Pediatr 2012;12:189.

63. Bei B, Byrne ML, Ivens C, Waloszek J, Woods MJ, Dudgeon P, et al. Pilot study of a mindfulness-based, multi-component, in-school group sleep intervention in adolescent girls. Early Interv Psychiatry 2013;7:213-220.

64. Dewald-Kaufmann JF, Oort FJ, Meijer AM. The effects of sleep extension on sleep and cognitive performance in adolescents with chronic sleep reduction: an experimental study. Sleep Med 2013;14:510-517.

65. Sousa IC, Souza JC, Louzada FM, Azevedo CVM. Changes in sleep habits and knowledge after an educational sleep program in 12th grade students. Sleep Biol Rhythms 2013;11:144-153.

66. Beijamini F, Louzada FM. Are educational interventions able to prevent excessive daytime sleepiness in adolescents? Biol Rhythm Res 2012;43:603613 .

67. Wing YK, Chan NY, Man Yu MW, Lam SP, Zhang J, Li SX, et al. A schoolbased sleep education program for adolescents: a cluster randomized trial. Pediatrics 2015;135:e635-e643.

68. Kira G, Maddison R, Hull M, Blunden S, Olds T. Sleep education improves the sleep duration of adolescents: a randomized controlled pilot study. J Clin Sleep Med 2014;10:787-792.

69. Kuhn BR, Elliott AJ. Treatment efficacy in behavioral pediatric sleep medicine. J Psychosom Res 2003;54:587-597.

70. Mindell JA, Kuhn B, Lewin DS, Meltzer LJ, Sadeh A; American Academy of Sleep Medicine. Behavioral treatment of bedtime problems and night wakings in infants and young children. Sleep 2006;29:1263-1276.

71. Owens JA, Palermo TM, Rosen CL. Overview of current management of sleep disturbances in children: II-Behavioral interventions. Curr Ther Res 2002;63(Supplement B):B38-B52.

72. Hart CN, Hawley NL, Wing RR. Development of a behavioral sleep intervention as a novel approach for pediatric obesity in school-aged children. Sleep Med Clin 2016;11:515-523.

73. Scheer FA, Hilton MF, Mantzoros CS, Shea SA. Adverse metabolic and cardiovascular consequences of circadian misalignment. Proc Natl Acad Sci U S A 2009;106:4453-4458.

74. Sakurai T. The neural circuit of orexin (hypocretin): maintaining sleep and wakefulness. Nat Rev Neurosci 2007;8:171-181.

75. Hanlon EC, Van Cauter E. Quantification of sleep behavior and of its impact on the cross-talk between the brain and peripheral metabolism. Proc Natl Acad Sci U S A. 2011;108 Suppl 3:15609-15616.

76. Sánchez-Ortuño MM, Bélanger L, Ivers $\mathrm{H}$, LeBlanc M, Morin CM. The use of natural products for sleep: a common practice? Sleep Med 2009;10:982987.

77. Valtonen M, Niskanen L, Kangas AP, Koskinen T. Effect of melatonin-rich night-time milk on sleep and activity in elderly institutionalized subjects. Nord J Psychiatry 2005;59:217-221.

78. Pigeon WR, Carr M, Gorman C, Perlis ML. Effects of a tart cherry juice beverage on the sleep of older adults with insomnia: a pilot study. J Med Food 2010;13:579-583.

79. Garrido M, Paredes SD, Cubero J, Lozano M, Toribio-Delgado AF, Muñoz
JL, et al. Jerte Valley cherry-enriched diets improve nocturnal rest and increase 6-sulfatoxymelatonin and total antioxidant capacity in the urine of middle-aged and elderly humans. J Gerontol A Biol Sci Med Sci 2010;65: 909-914.

80. Lin HH, Tsai PS, Fang SC, Liu JF. Effect of kiwifruit consumption on sleep quality in adults with sleep problems. Asia Pac J Clin Nutr 2011;20:169-174.

81. Weiss A, Xu F, Storfer-Isser A, Thomas A, Ievers-Landis CE, Redline S. The association of sleep duration with adolescents' fat and carbohydrate consumption. Sleep 2010;33:1201-1209.

82. Al-Disi D, Al-Daghri N, Khanam L, Al-Othman A, Al-Saif M, Sabico S, et al. Subjective sleep duration and quality influence diet composition and circulating adipocytokines and ghrelin levels in teen-age girls. Endocr J 2010;57:915-923.

83. Grandner MA, Kripke DF, Naidoo N, Langer RD. Relationships among dietary nutrients and subjective sleep, objective sleep, and napping in women. Sleep Med 2010;11:180-184.

84. Diethelm K, Remer T, Jilani H, Kunz C, Buyken AE. Associations between the macronutrient composition of the evening meal and average daily sleep duration in early childhood. Clin Nutr 2011;30:640-646.

85. Peuhkuri K, Sihvola N, Korpela R. Diet promotes sleep duration and quality. Nutr Res 2012;32:309-319.

86. van Zyl LT, Chung SA, Shahid A, Shapiro CM. L-tryptophan as treatment for pediatric non-rapid eye movement parasomnia. J Child Adolesc Psychopharmacol 2018;28:395-401.

87. Koren D, Taveras EM. Association of sleep disturbances with obesity, insulin resistance and the metabolic syndrome. Metabolism 2018;84:67-75.

88. Pervanidou P, Bastaki D, Chouliaras G, Papanikolaou K, Laios E, KanakaGantenbein C, et al. Circadian cortisol profiles, anxiety and depressive symptomatology, and body mass index in a clinical population of obese children. Stress 2013;16:34-43.

89. Krietsch KN, Chardon ML, Beebe DW, Janicke DM. Sleep and weight-related factors in youth: a systematic review of recent studies. Sleep Med Rev 2019;46:87-96.

90. Hayes JF, Balantekin KN, Altman M, Wilfley DE, Taylor CB, Williams J. Sleep patterns and quality are associated with severity of obesity and weightrelated behaviors in adolescents with overweight and obesity. Child Obes 2018;14:11-17.

91. Knutson KL, Turek FW. The U-shaped association between sleep and health: the 2 peaks do not mean the same thing. Sleep 2006;29:878-879.

92. Li X, Lin L, Lv L, Pang X, Du S, Zhang W, et al. U-shaped relationships between sleep duration and metabolic syndrome and metabolic syndrome components in males: a prospective cohort study. Sleep Med 2015;16:949954.

93. Liu Y, Wheaton AG, Croft JB, Xu F, Cunningham TJ, Greenlund KJ. Relationship between sleep duration and self-reported health-related quality of life among US adults with or without major chronic diseases, 2014. Sleep Health 2018;4:265-272. 